\title{
Psychological Capital Research in India: A Review and Critique
}

\author{
Ms Roshni James ${ }^{1}$, Dr A. M Suresh ${ }^{2}$
}

\section{ABSTRACT}

Psychological capital (PsyCap) draws from the significant body of research that Seligman and Csikszentmihalyi have initiated in the wake of the positive psychology movement. The article introduces the concept of psychological capital which is created by Fred Luthans and his colleagues. The main purpose of this article is to position the psychological capital research status in India. The article also highlights the gap in the area which helps the researchers to identify areas for further study.

Keywords: Psychological Capital

Psychological Capital can be defined as: “An individual's positive psychological state of development that is characterized by: having confidence (self-efficacy) to take on and put in the necessary effort to succeed at challenging tasks; making a positive attribution (optimism) about succeeding now and in the future; persevering toward goals, and when necessary, redirecting paths to goals (hope) in order to succeed; and when beset by problems and adversity, sustaining and bouncing back and even beyond (resiliency) to attain success" (Luthans, Youssef, \& Avolio, 2007 p. 3) Each of these components of PsyCap have a background in theory and research; can be measured; can be developed over time and has a positive impact on performance (see Luthans, 2002; Luthans \& Youssef, 2004).

\section{Objectives of the Study:}

The aim of this article is to review significant research that has been conducted in the field of Psychological Capital in India. in order to understand the growth of the positive psychology movement since it began at the turn of the new millennium.

\footnotetext{
${ }^{1}$ MBA, M.Phil, Ph.D scholar, Bharathiar university, Associate Professor, The Oxford College of Business Management, HSR layout Bangalore, India

${ }^{2}$ MBA, M.Phil, Ph.D, Managing Director at Disciples India Educational Resources Pvt Ltd, Bangalore., Research supervisor, Bharathiar university, Coimbatore, India

*Responding Author

(C) 2016 R James, A Suresh; licensee IJIP. This is an Open Access Research distributed under the terms of the Creative Commons Attribution License (http://creativecommons.org/licenses/by/2.0), which permits unrestricted use, distribution, and reproduction in any Medium, provided the original work is properly cited.
} 


\section{Psychological Capital Research in India: A Review and Critique}

\section{Research design:}

The research was based on search of secondary data from various sources on the internet. Google scholar was the primary data source for identifying and selection of relevant articles. In addition to the word psychological capital the key word India was also used in the advanced search option. Only conceptual or empirical research articles were used for the study. In order to minimize the risk of losing out on relevant data a few journals on psychology was also looked into during the study. A extensive search of the existing literature from India of the articles was done to identify similarities among the studies to evolve themes from it. The studies cited in this paper is from journals listed on Google scholar.

There are a few studies that have gone beyond relatively static constructs such as demographics and personality to examine the role of dynamic construct of psychological capital on various aspects. The various themes on which the studies are done are found to be commitment, satisfaction, leadership and well being.

Commitment: a significant portion of the studies on psychological capital in India is on its impact on commitment and also the citizenship behavior. Some of them to mention is as below. This paper Psychological Capital as Predictor of Organizational Commitment and Organizational Citizenship Behavior Prof. Anu Singh Lather , Ms. Simran Kaur(2015) examined psychological capital in two types of organizations: public and private schools. This study explained how psychological capital effects organizational commitment and organizational citizenship behavior in public and private schools. The sample includes 150 employees, 75 each from two types of schools. Various dimensions of Psychological Capital were measured by scale developed by Luthan, Youssef \& Avolio. Organizational Commitment was measured by Allen \& Meyer's scale and Organizational Citizenship Behavior by a scale developed by Podsakoff. The result obtained from Pearson correlation and stepwise multiple regressions and it showed that all the dimensions of psychological capital were significantly different in the both the kind of schools. Regression analyses showed that psychological capital as a whole can predict organizational commitment and organizational citizenship behavior in both kinds of schools.

Study by Bharat Chandra Sahoo and suresh kumar sia(2015) based their study on the sample of 276 employees (150 male, 126 female) from three manufacturing units in India. It was based on the context that scales were not validated or standardized in the Indian context and direct application of such scales to the Indian population is sometimes not practical due to differences in culture, belief, language and lifestyle the authors carried out factor analyses involving both exploratory factor analysis (EFA) and confirmatory factor analysis (CFA) on psychological capital questionnaire by Luthans, Avolio, Avey and Norman (2007) and CFA for organizational commitment scale by Mowday, Steers and Porter (1979). The study involves The EFA of psychological capital suggested a three factors model instead of a four factors model. When it was estimated with CFA, the three factors measurement model was more well fitted than single 


\section{Psychological Capital Research in India: A Review and Critique}

factor as well as four factors models. The series of CFAs conducted for the organizational commitment scale through the measurement model reported that two factors structure is good enough to measure commitment behavior. Structural equation modeling (SEM) analysis reports that psychological capital contributes significantly to organizational commitment

In a study by Shukla, A., \& Singh, S. (2013). on 368 junior and mid-level IT executives from India exploring the role of perceived organizational support (POS) in developing organizational trust and organizational commitment and the moderating effect of psychological capital therein. A self-reported questionnaire survey was conducted among POS was found to be positively related to the aforementioned variables and the relationships witnessed attenuation at higher levels of psychological capital.

Promila Agarwal(2011): The study empirically links the relationship between Psychological Contract and Organization Commitment in the Indian IT industry The correlation design is used here to understand the relationship between psychological contract and employee's intent to stay with the organization. The results showed that 'intent to stay' and value commitments are significantly and positively correlated with psychological contract. The study highlights the importance of psychological contract and its detrimental effects on human capital, if ignored.

Amit Shukla \& Shailendra Singh (2013)attempts by a cross sectional survey to examine the mediating role played by job satisfaction between Psychological Capital and OCB. A selfreported paper based questionnaire survey was conducted on mid-level managers $(\mathrm{N}=172)$ from a large Indian telecom company. Statistical analysis revealed that Psychological Capital was a better predictor of job satisfaction as compared to OCB and the that both psychological capital and work engagement have significant impact on the organizational citizenship behavior of the employees.

Rabindra Pradhan, L Kesari (2016)did a study on 212 professionals in Indian manufacturing and service industries. investigated the relationship between psychological capital (Psycap) on organizational citizenship behavior (OCB) whether the construct of EI plays a role in moderating the relationships between Psycap and OCB using SEM. The results show that Psycap is positively related to OCB.

\section{Leadership}

Khan (2010): examined the relationship between Positive Psychological Capital (Luthan's Model), Leadership Behavior Model (Don Clark) and Leadership Behavior Description Questionnaire (adapted by J. William Pfeiffer and John E. Jones) on a sample of 105 students randomly selected amongst entrants/ students pursuing their PGDBM at a premier institute of Central India. These respondents were subjected to 4 measures of PPC including Optimism, Hope, Resiliency, and Self-efficacy/ confidence, 2 measures of Leadership Behavior Model of 


\section{Psychological Capital Research in India: A Review and Critique}

task oriented or people oriented and the same measures through Leadership Behavior Description Questionnaire, helping define an individual's leadership style used and its effectiveness. The analysis of these measures reveal that the constructs of PPC and Leadership are significantly correlated suggesting that PsyCap can serve as an effective predictor of Effective Global leadership amongst MBA students.

Satisfaction: study by Swati Chaudhary, J.S. Bidlan and C.R. Darolia (2015)examines the relationship between psychological capital, job satisfaction and turnover intention of LIC employees a leading insurance company in India. A sample of 124 employees including 100 males and 24 females is selected for the investigation. PsyCap was measured with the use of the 24-item psychological capital questionnaire (PCQ) by Luthans, Youssef, and Avolio (2007). The Job Satisfaction Scale (JSS) was developed by Muthayya (1973) and Turnover Intention assessed through Shore and Martin (1989) scale. Findings of study show that there is a positive significant correlation between psychological capital and job satisfaction and psychological capital and turnover intention. It is also reveals that there is significant difference in male and female's job satisfaction but no significant difference is observed in turnover intention.

Performance study by Gupta, V. (2013) presents psychological capital as an important mediating variable for the relationship between high-performance HRM practices and employee creativity.

Well being: Dr. Chandrani Sen, R Hooja(2015)The study on 50 police officers posted in Rajasthan ( $\mathrm{N}=50)$ explored the relationship between the core constructs of psychological capital ( hope, optimism, resilience and efficacy) with work-life balance. The study was conducted using Psychological Capital Questionnaire (PCQ) developed by Luthans, Youssef, Avolio (2007) and Work life balance questionnaire developed by Haddon(2008). Correlation design was used to analyze the data. Results revealed that psychological capital and work-life balance were positively related, wherein only efficacy, one of the construct of psychological capital, significantly related to work-life balance.

Nayanika Singh \& Aadi Garg(2014) in their study attempted to assess the effect of gender on Psychological capital and Personal Wellbeing among male and female teachers. The sample consisted of 100 teachers (50 from each gender) randomly selected from colleges of Chandigarh, age ranging, 35-50 years, having at least five years of teaching experience. The tools used for the present study consisted of the Psychological Capital Questionnaire and the Personal Wellbeing index for adults. The T-test was used for the purpose of statistical interpretation to assess the significance of difference between the two means for male and female teachers

K. C. Barmola (2013)in a study on of 100 adolescent has been selected randomly from a public school Jaipur, (Rajasthan: India) in which 50 are male and 50 are female. Find out the gender 


\section{Psychological Capital Research in India: A Review and Critique}

differences (with various dimensions of the scale) among adolescents in terms of positive psychological capital. Study say that overall there is no significant gender difference is found among adolescents in terms of positive psychological capital. Having four dimensions (hope, self-efficacy, optimism and resiliency) of the test, each of them is analyzed separately. In the comparison of dimensions no gender difference is found on self-efficacy, optimism and resiliency but it is found significant on hope $(\mathrm{t}=2.77)$ at 0.01 level. Therefore it may be estimated that there can be gender difference only in terms of hope among adolescents but not in other dimensions.

Sihag, P \& Sarikwal, L. (2014). The study focuses on the relationship between PsyCap and employee engagement. Data from 420 middle level IT professionals (working in different IT industries in Indian context) were collected for current study. Regression analysis, basic descriptive analysis, Confirmatory factor analysis, model fit analysis etc. analysis were performed. Results revealed positive impact of PsyCap on Employee Engagement. Results of current study demonstrated that employee with higher level of PsyCap (in terms of hope, confidence level, bounce back capability and optimistic view) show higher level of work engagement at workplace in IT industries.

Abhishek Kumar Totawar and Ranjeet Nambudiri (2016) in their study identifies psychological capital (PsyCap) as an explanatory mechanism for the influence of organizational justice on job satisfaction and organizational commitment on the basis of social exchange theory, and 'broaden and build' theory of positive emotions, It tested a theoretical and structural model that hypothesized mediation of PsyCap in the influence of organizational justice on job satisfaction and organizational commitment. A survey-based methodology, with standardized scales was used. A sample of 440 employees from the Indian service sector industry was drawn. A two-step process of analysis, with AMOS 16, was employed to test the structural model. Besides examining the significance of indirect effects using the bias-corrected confidence intervals with two-thousand bootstrap samples, the study also applied alternative/nested structural equation models to test the mediation hypotheses. Results are found to be consistent with the stated hypotheses thus confirming the mediation of PsyCap in the influence of organizational justice on job satisfaction and organizational commitment. It also supports and extends the view of previous researchers that PsyCap is a significant positive organizational behavior (POB) variable, as it is capable of performance improvement and is open to development. From a managerial perspective, given the 'open to control' nature of PsyCap, it renders a significant tool in the hands of managers to control the satisfaction and commitment of their employees. Moreover, controlling PsyCap is much easier as compared to directly controlling justice perceptions. 


\section{Psychological Capital Research in India: A Review and Critique}

\section{Observations and critique:}

Positive psychology as a field of study is seen to have begun but growing at a snail pace in India. The importance of positive psychology as a subject is found to be growing with the spur of various associations like Indian association of positive psychology, national positive psychology association, etc. The acceptance of the field is also reflected in the fact that many institutions provide certification programs in positive psychology like IIT Delhi and NIMHANS Bangalore Indian institute of positive psychology. Journals specific to positive psychology is also begun though at the infancy stage.

The period of 2012 to 2015 so far has been the period during which the maximum studies are being conducted and the authors are from across the geographical locations of the country. The studies on psychological capital are done in the area of telecom, police department, educational sector etc. but majority of the studies on psychological capital in India are done in the field of information technology. It is observed that all studies done in the area of psychological capital are done using quantitative analysis adopting the PCQ24 scale by Fred Luthans.

Though many a studies mentions that the tool is not adapted to the Indian scenario less attempts have been made to develop a new scale for the measurement of psychological capital to suit the Indian scenario. Though there are studies that emphasize the importance of using qualitative methodology to understand participant experiences completely very little or even no study is reported so far on the assessment of psycap as a qualitative study in India. As the constructs of psycap are experiences by itself it would help to bring out the different angles of confidence optimism hope and resilience from a qualitative study. It is interesting to note that most of the focus of positive intervention studies has so far been on yoga or spirituality.

\section{Acknowledgments}

The author appreciates all those who participated in the study and helped to facilitate the research process.

\section{Conflict of Interests}

The author declared no conflict of interests.

\section{REFERENCES}

Agarwal, P. (2011). Relationship between psychological contract \& organizational commitment in Indian IT industry. Indian Journal of Industrial Relations, 290-305.

Chaudhary, S., Bidlan, J. S., \& Darolia, C. R. (2015). A study of relationship of psychological capital with job satisfaction and turnover intention of LIC employees. Indian Journal of Health and Wellbeing, 6(7), 692.

Dovina, D. T., \& Karunanidhi, S. (2013). The influence of positive psychological capital and work attitude on the performance of employees in ITES. Indian Journal of Positive Psychology, 4(1), 1. 


\section{Psychological Capital Research in India: A Review and Critique}

Dr. Chandrani Sen, Himangini R Hooja (2015)Psychological Capital and Work-life Balance: A Study on Police Officers

Dr. Rita Karmakar (2016) Positive psychological capital: Does this promote the use of functional and dysfunctional coping strategy?

Gupta, V. (2013). Development of a casual framework linking high performance HRM practices, positive psychological capital, creative behaviors and performance.

Gupta, V., \& Singh, S. (2014). Psychological capital as a mediator of the relationship between leadership and creative performance behaviors: Empirical evidence from the Indian R\&D sector. The International Journal of Human Resource Management, 25(10), 1373-1394.

Ho, V., Whitaker, J., Mithas, S., \& Roy, P. K. (2012). It's What's Inside that Counts: The Role of Social and Psychological Capital in Compensation for Offshore BPO Professionals.

Jena, L. K., \& Pradhan, R. K. (2015). Psychological capital and workplace spirituality: role of emotional intelligence. International Journal of Work Organization and Emotion, 7(1), 1-15.

Khan, S. (2010). Positive psychological capital: a correlate of effective global leadership. Res $J$ social science \& management, 1(8).

Kirmani, M. N., \& Jahan, F. (2015). Exploring psychological capital among bank employees: Exploring human potential. Indian Journal of Positive Psychology, 6(1), 79.

Kirmani, M. N., Sharma, P., Anas, M., \& Sanam, R. (2015)Hope, Resilience and Subjective Well-being among college going Adolescent Girls.

Lather, A. S., \& Kaur, M. S. (2015). Psychological Capital as Predictor of Organizational Commitment and Organizational Citizenship Behavior.

Murthy, R. (2014). Psychological Capital, Work Engagement and Organizational Citizenship Behaviour. Sinhgad Institute.

Rabindra Kumar Pradhan, Lalatendu Kesari Jena(2016) Impact of psychological capital on organizational citizenship behavior: Moderating role of emotional intelligence Cogent Business \& Management, Volume 3, Issue 1, December 2016

Saharan, S., \& Jain, (2014)M. Positive Psychological Capital In Relation To Job Satisfaction: A Study of School Female Teachers.

Sahoo, B. C., \& Sia, S. K. (2015). Psychological Capital and Organizational Commitment: Nature, Structure and Relationship in an Indian Sample. Asia-Pacific Journal of Management Research and Innovation, 11(3), 230-244.

Sen, C., \& Hooja, H. R. (2015). Developing Indian human resource: Role of psychological capital and protean career orientation. Indian Journal of Positive Psychology, 6(3).

Sen, C., \& Hooja, H. R. Psychological Capital and Work-life Balance: A Study on Police Officers.

Shukla, A., \& Rai, H. (2014). Interactive effects of psychological capital and perceived support in developing trust and commitment among Indian IT executives. Employment Relations Record, 14(2), 66.

Shukla, A., \& Singh, S. (2013). Psychological capital \& citizenship behavior: evidence from telecom sector in India. Indian Journal of Industrial Relations,49(1), 97-111. 


\section{Psychological Capital Research in India: A Review and Critique}

Sihag, P., \& Sarikwal, L. (2014). Impact of Psychological Capital on Employee Engagement: A Study of IT Professionals in Indian Context. Management Studies and Economic Systems, 1(2), 127-139.

Sihag, P., \& Sarikwal, L. (2015). Effect of perceived organizational support on psychological capital-A study of IT industries in Indian framework.

Singh, P. (2015). Well-being: Role of psychological capital among employees. Indian Journal of Positive Psychology, 6(3).

Srivastava A, Ramachandran, K., \& Suresh, A. (2014). Predictors of employee engageent in organization. Asia Pacific Journal of Research Vol: I Issue XVIV.

How to cite this article: R James, A Suresh (2016), Psychological Capital Research in India: A Review and Critique, International Journal of Indian Psychology, Volume 3, Issue 4, No. 75, ISSN:2348-5396 (e), ISSN:2349-3429 (p), DIP:18.01.059/20160304, ISBN:978-1-365-50727-4 